\title{
Painful ovulation in a 46,XX SRY - ve adult male with SOX9 duplication
}

\author{
Nandini Shankara Narayana1,2, Anne-Maree Kean', Lisa Ewans',3, Thomas Ohnesorg4, \\ Katie L Ayers4,5, Geoff Watson', Arthur Vasilaras', Andrew H Sinclair ${ }^{4,5}$, \\ Stephen M Twigg' and David J Handelsman²
}

${ }^{1}$ Royal Prince Alfred Hospital, Sydney, New South Wales, Australia, ${ }^{2}$ ANZAC Research Institute, University of Sydney, Sydney, New South Wales, Australia, ${ }^{3}$ Central Clinical School, Sydney Medical School, University of Sydney، New South Wales, Australia, ${ }^{4}$ Murdoch Childrens Research Institute, Melbourne, Victoria, Australia, and ${ }^{5}$ Department of Paediatrics, University of Melbourne, Melbourne, Victoria, Australia

\author{
Correspondence \\ should be addressed \\ to N Shankara Narayana \\ Email \\ nsha7690@uni.sydney.edu.au
}

\section{Summary}

$46, X X$ disorders of sexual development (DSDs) occur rarely and result from disruptions of the genetic pathways underlying gonadal development and differentiation. We present a case of a young phenotypic male with 46,XX SRY-negative ovotesticular DSD resulting from a duplication upstream of SOX9 presenting with a painful testicular mass resulting from ovulation into an ovotestis. We present a literature review of ovulation in phenotypic men and discuss the role of $S R Y$ and SOX9 in testicular development, including the role of SOX9 upstream enhancer region duplication in female-to-male sex reversal.

\section{Learning points:}

- In mammals, the early gonad is bipotent and can differentiate into either a testis or an ovary. SRY is the master switch in testis determination, responsible for differentiation of the bipotent gonad into testis.

- SRY activates SOX9 gene, SOX9 as a transcription factor is the second major gene involved in male sex determination. SOX9 drives the proliferation of Sertoli cells and activates AMH/MIS repressing the ovary. SOX9 is sufficient to induce testis formation and can substitute for SRY function.

- Assessing karyotype and then determination of the presence or absence of Mullerian structures are necessary serial investigations in any case of DSD, except for mixed gonadal dysgenesis identified by karyotype alone.

- Treatment is ideal in a multidisciplinary setting with considerations to genetic (implications to family and reproductive recurrence risk), psychological aspects (sensitive individualized counseling including patient gender identity and preference), endocrinological (hormone replacement), surgical (cosmetic, prophylactic gonadectomy) fertility preservation and reproductive opportunities and metabolic health (cardiovascular and bones).

\section{Background}

DSDs result from disruptions to the delicate balance of the molecular pathways in the male and female sexdetermining pathways. They can present at any age ranging from prenatal state, at birth (e.g., hypospadias, ambiguous genitalia, etc.) to early adulthood (delayed puberty, infertility). They can be extremely challenging owing to the associated diagnostic and ethical dilemmas. DSDs are rare and need a 
systematic approach to establish diagnosis through a multidisciplinary approach.

\section{The case}

A 17-year-old Caucasian male presented with a twoday history of a painful mass in left testis. There was no history of trauma, fever or weight loss. His pubertal development was normal. His medical history included right cryptorchidism with spontaneous descent at one year of age, Henoch-Schonlein purpura at four years, excision of a benign left extra adrenal ganglioneuroma at five years without recurrence, pyelonephritis at fourteen years and an upper lip capillary haemangioma.

He was the only child to a non-consanguineous couple who had three previous miscarriages. His father died aged 63 years from chronic lung disease secondary to asbestos exposure (Pedigree Chart, Fig. 1). Three first cousins had precocious puberty.

His height was $1.77 \mathrm{~m}$ (mother $1.75 \mathrm{~m}$, father $1.68 \mathrm{~m}$ ), weight $68.8 \mathrm{~kg}$, with Tanner stage 4 pubertal development and small bilateral gynaecomastia, but no acne. By orchidometry, the left testis was $8 \mathrm{~mL}$, containing a tender solid $2 \mathrm{~cm}$ mass and a large left hydrocele and the right testis was atrophic and $1 \mathrm{~mL}$.

\section{Investigations}

Scrotal ultrasound demonstrated an atrophic right $(3 \mathrm{~mL})$ and a larger left testis containing a solid lesion $2 \mathrm{~cm}$ in diameter, suggestive of a neoplasm and a $22 \mathrm{~mL}$ left hydrocele. CT scan of the chest and abdomen did not show evidence of metastatic disease or abnormal lymph nodes; the seminal vesicles and prostate were normal.

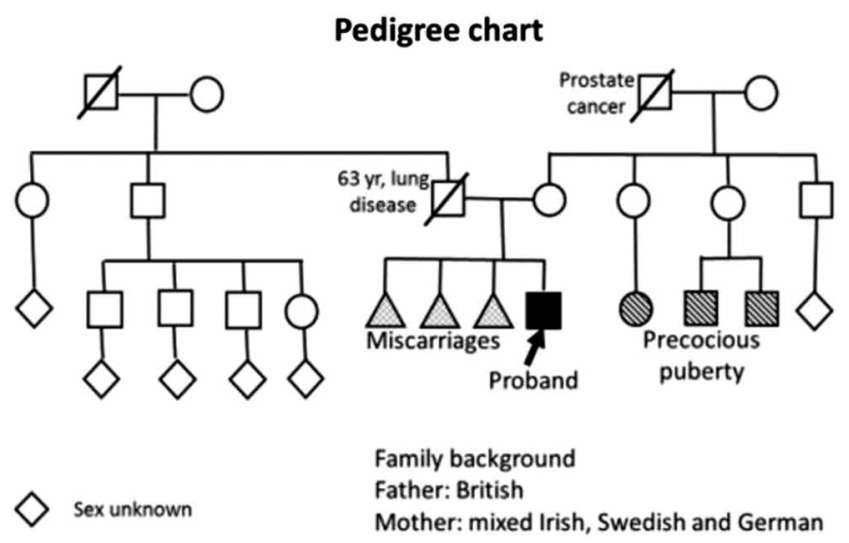

Figure 1

Pedigree chart.
He had elevated serum FSH (17.2 IU/L) and LH $(11.7 \mathrm{IU} / \mathrm{L})$, low serum testosterone $(5.1 \mathrm{nmol} / \mathrm{L})$ and normal serum SHBG $(24 \mathrm{nmol} / \mathrm{L})$. Serum $\alpha \mathrm{FP}$ and HCG were negative. Semen analysis showed azoospermia. The working diagnosis was a testicular tumor on a background of possible Klinefelter syndrome.

\section{Treatment and follow-up}

Left partial orchidectomy was performed. Macroscopically the mass was a hematoma. Histopathology showed a hemorrhagic corpus luteal cyst within an ovotestis (Fig. 2A, $\mathrm{B}, \mathrm{C}$ and $\mathrm{D})$. The gonad, including the ovarian tissue, was contained within a tunica albuginea. The testicular tissue contained Sertoli-cell-only seminiferous tubules, interstitial Leydig cells and some Sertoli cell nodules. The ovarian tissue comprised ovarian stroma, a few primordial follicles (the only germ cells in the ovotestis), a hemorrhagic corpus luteum and several corpora albicans.

Karyotype was 46,XX with a notably absent $S R Y$ signal on FISH analysis. The ovarian and testicular tissue both had confirmed 46,XX chromosomes without $\mathrm{Y}$ signal. Radiological bone age (wrist) was consistent with

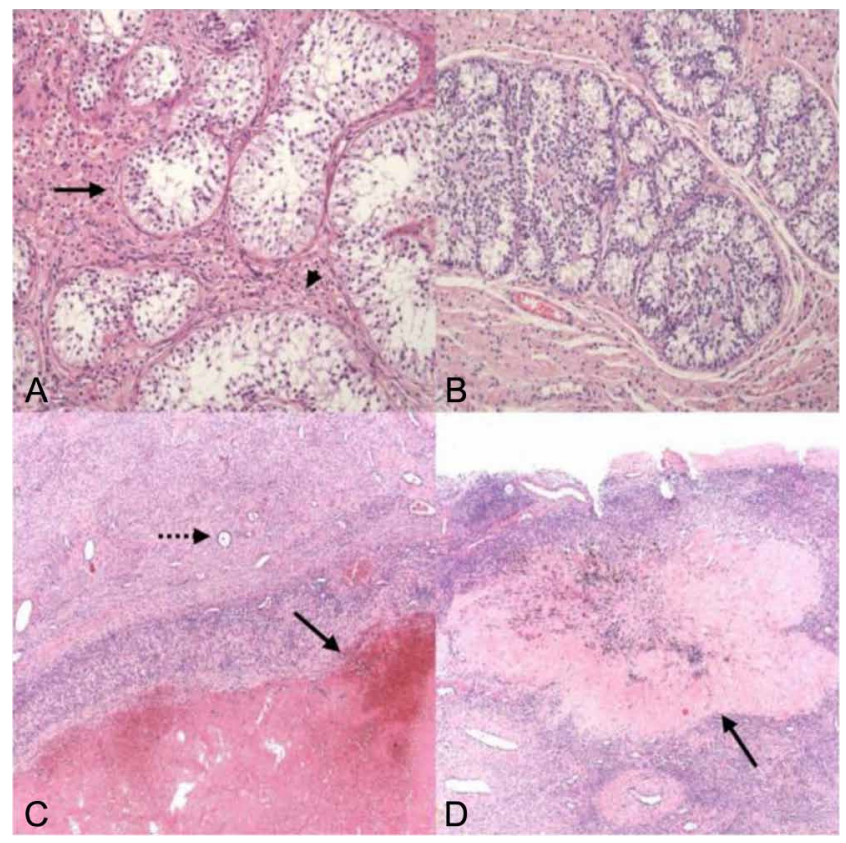

Figure 2

Ovo-testis histology. (A) Seminiferous tubules (arrow), devoid of germ cells or spermatogenesis, with interstitial Leydig cells (arrow head). (B) Sertoli cell nodule in testicular component (Leydig-rich background). (C) Ovarian tissue with an involuting haemorrhagic corpus luteum (arrow) and a primordial follicle (dotted arrow). (D) Ovarian tissue with an old corpus albicans (arrow), the adjacent ovarian stroma with a further primordial follicle. Image dimensions, $A$ and $B: 0.9 \times 0.7 \mathrm{~mm} ; C$ and D: $2.2 \times 1.7 \mathrm{~mm}$. 
chronological age. Post-operatively, both serum FSH (38.2 IU/L) and LH (22.7 IU/L) rose further with a serum total testosterone of $8.7 \mathrm{nmol} / \mathrm{L}$.

Repeat genetic testing on DNA extracted from blood, confirmed the absence of $S R Y$ and a 46,XX karyotype (1). This classified the diagnosis as 46,XX SRY negative (-ve) ovotesticular DSD. Further analysis identified a duplication upstream of the SOX9 gene, which was confirmed by a second independent method (2).

The proband's mother did not carry the duplication, however there was no paternal family history of DSD or infertility.

Within a multidisciplinary team, as the patient's gender identity was unequivocally male, he was managed as a young man with hypogonadism requiring testosterone replacement and counseling regarding irreversible infertility associated with a missing $\mathrm{Y}$ chromosome. He was treated with injectable testosterone undecanoate (1000 mg, per 12 weeks), which achieved Tanner stage 5 virilization with gain of muscle bulk and acne. His most recent trough serum total testosterone concentration was $9.6 \mathrm{nmol} / \mathrm{L}$ with suppressed serum LH ( $<0.1 \mathrm{IU} / \mathrm{L})$ and FSH $(0.8 \mathrm{IU} / \mathrm{L})$, indicating adequate replacement therapy.

\section{Discussion}

In mammals, the early gonad is bipotential and can differentiate into either a testis or an ovary. SRY is the master switch in testis determination (3) having evolved from the ancestral SOX3 (SRY type high-mobility group box gene) gene. $S R Y$ (sex-determining region on the $\mathrm{Y}$ chromosome) is specific to mammals (4). $S R Y$ upregulation of SOX9 induces differentiation of the bipotential gonad into a testis and, in its absence, the genital ridge develops by default into ovaries.

The only known function of $S R Y$ is to upregulate the evolutionarily more conserved SOX9 (5), an autosomal (chromosome 17) gene. SRY-induced SOX9 activation drives Sertoli cell differentiation and proliferation, a decisive step in testis development $(4,5)$. SRY is sufficient but not necessary for testis development, as increased SOX9 expression, is sufficient to induce testis formation, thus substituting for $S R Y$ function (6). Ectopic expression of SOX9 in an XX gonad induces testis development in transgenic XX mice (6) while SOX9 duplication can cause XX sex reversal in humans (7). Furthermore, experimentally replacing SOX9 for Sry, and Eif2s3x for Eif2s3y (spermatogonial proliferation factor) in mice produced phenotypic males with testes despite the absence of the $\mathrm{Y}$ chromosome. These two genes alone were sufficient to produce fertile haploid male gametes that could fertilize oocytes in vitro and produce offspring (8).

SOX9 is a pleiotropic gene with an array of gene dosage effects. Inactivation of both $S O X 9$ alleles leads to the formation of ovaries in XY mice (9). In humans, SOX9 gene haploinsufficiency causes campomelic dysplasia (CD), an autosomal dominant skeletal dysplasia, as well as male-to-female sex reversal in about $75 \%$ of the $46, X Y$ patients (10). SOX9 is also implicated in pancreatic development with pancreatic hypoplasia reported in patients with CD and in mouse models (11). SOX9 regulates neural crest development and ectopic expression of SOX9 in the neural tube progenitors results in neural crest-like properties (12). These links to neural crest development could explain the benign extra adrenal ganglioneuroma in this patient.

Our 46,XX $S R Y$-ve patient had a novel duplication in the regulatory region upstream of $S O X 9$, leading to a male phenotype (2). He had at least one ovotestis that produced sufficient testosterone to almost complete a phenotypically normal male puberty but not sufficient to suppress ovulation on more than one occasion, as shown by the apparent recent ovulation as indicated by a

Table 1 Hormonal profile pre-operatively, post-operatively and on testosterone replacement therapy.

\begin{tabular}{|c|c|c|c|c|c|c|c|}
\hline \multirow[b]{2}{*}{ Hormonal panel } & \multicolumn{5}{|c|}{ Results } & \multicolumn{2}{|c|}{ Reference range } \\
\hline & 15 days pre-op & 13 days pre-op & 2 months post-op & 6 months post T Rx & 14 months post $T$ Rx & Male & Female \\
\hline FSH (IU/L) & 13 & 17 & 38 & 3.3 & 0.8 & $1.0-12$ & $\begin{array}{l}\text { Follicular 3.5-12.5 } \\
\text { Mid-cycle 4.7-21.5 } \\
\text { Luteal 1.7-7.7 }\end{array}$ \\
\hline LH (IU/L) & 8 & 12 & 23 & 16 & $<0.1$ & $0.6-12$ & $\begin{array}{l}\text { Follicular 2.4-12.6 } \\
\text { Mid-cycle 14-95 } \\
\text { Luteal 1-11.4 }\end{array}$ \\
\hline $\begin{array}{l}\text { Testosterone } \\
\text { (nmol/L) }\end{array}$ & 4.5 & 5.1 & 8.7 & 9.6 & 9.7 & $11.5-32$ & $<2.8$ \\
\hline SHBG (nmol/L) & & 24 & & & & $15-80$ & \\
\hline
\end{tabular}




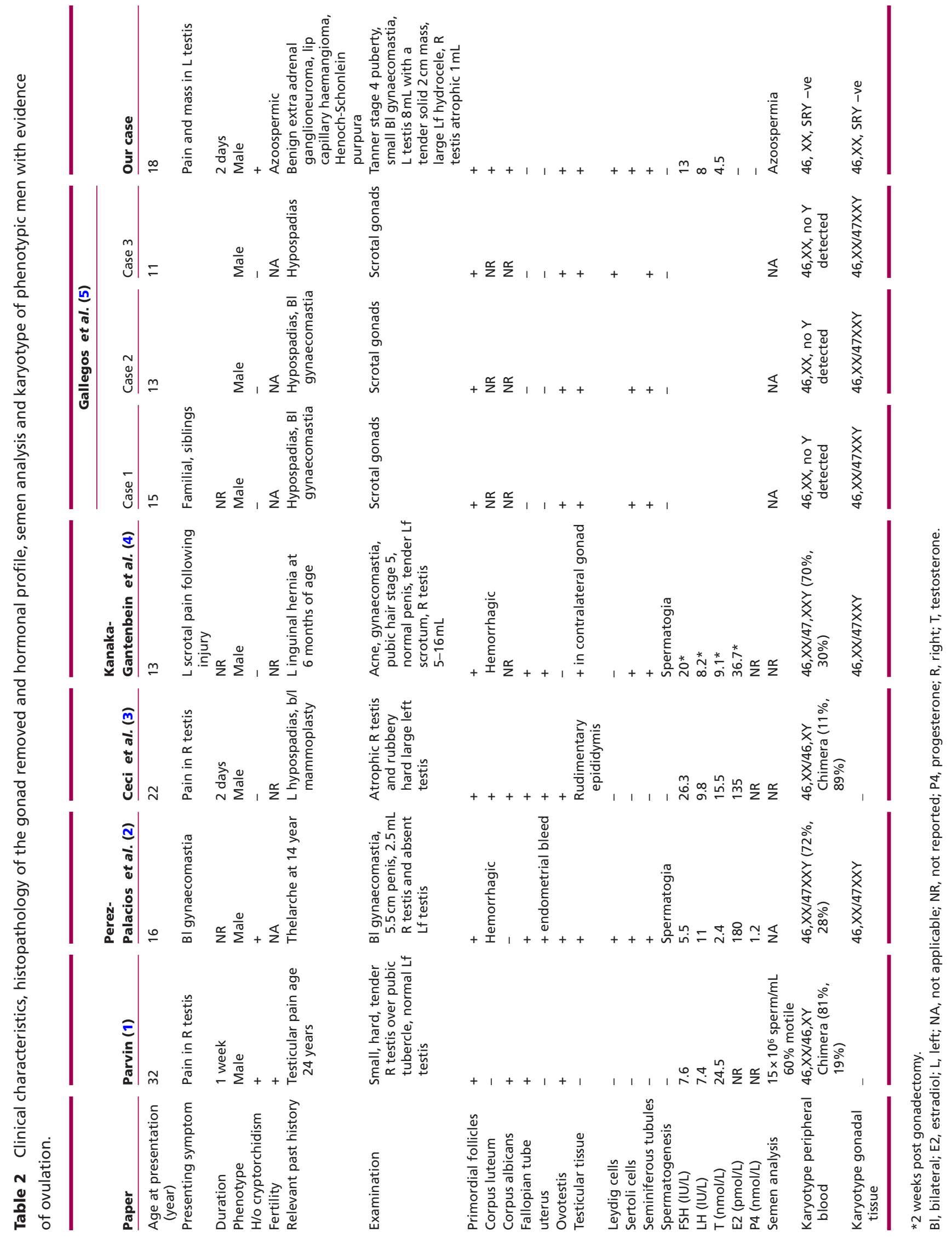



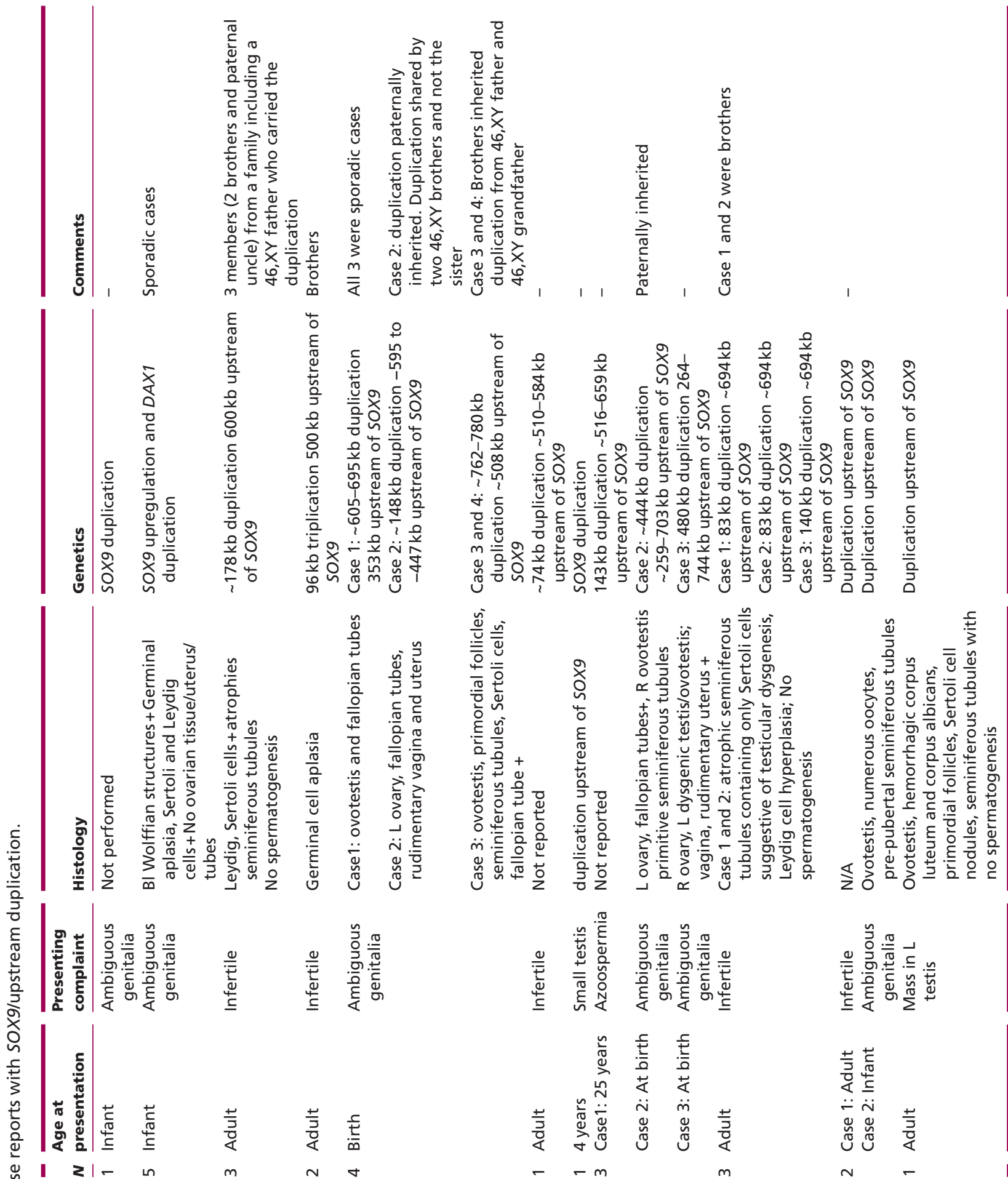
Table 4 Classification of DSDs, in particular 46,XX DSDs that can result in virilization or male phenotype (18).

\begin{tabular}{|c|c|}
\hline DSD category & Examples \\
\hline \multirow[t]{3}{*}{ Sex chromosome DSD } & Klinefelter's syndrome \\
\hline & Turner's syndrome \\
\hline & Ovotesticular DSD \\
\hline \multirow[t]{4}{*}{$46, X Y$ DSD } & Disorders of androgen action (androgen insensitivity syndrome) \\
\hline & Disorders of androgen biosynthesis \\
\hline & $\begin{array}{l}\text { Disorders of testicular development (ovotesticular DSD, testis } \\
\text { regression) }\end{array}$ \\
\hline & $\begin{array}{l}\text { Other syndromic associations of male genital development, isolated } \\
\text { hypospadias, cryptorchidism }\end{array}$ \\
\hline \multirow[t]{3}{*}{$46, X X$ DSD } & Disorders of ovarian development (ovotesticular DSD, testicular DSD) \\
\hline & $\begin{array}{l}\text { Disorders of androgen excess - fetal (congenital adrenal } \\
\text { hyperplasia), feto placental (aromatase deficiency) and maternal } \\
\text { (virilizing tumors e.g. luteomas) }\end{array}$ \\
\hline & $\begin{array}{l}\text { Other syndromic associations (e.g. cloacal anomalies), Mullerian } \\
\text { agenesis/hypoplasia, uterine abnormalities, vaginal atresia } \\
\text { (e.g. McKusick-Kaufman), labial adhesions }\end{array}$ \\
\hline
\end{tabular}

Karyotype or genes involved

$47, \mathrm{XXY}$ and variants/mosaics $45, X O$ and variants/mosaics $46, X X / 46, X Y$ chimerism $A R$ CYP11A1, HSD3B2, CYP17A1, StAR HSD17B3, SRD5A2, POR $D H H, S R Y, S F 1, W T 1$, SOX9

CXorf6, INSL3, GREAT

SRY, RSPO1, dup SOX3, dup SOX9* HSD3B2, CYP21A2, CYP11B1, POR, CYP19

MKKS

${ }^{*}$ Gene duplication detected in the current case of $46, X X$ karyotype in a young phenotypic male.

hemorrhagic corpus luteum as well as a corpus albicans, indicating prior ovulation. Given his male phenotype, no serum estradiol or progesterone concentrations were obtained pre-operatively nor did the hormonal levels (Table 1) confirm ovulation. It cannot be excluded that rather than true ovulation, the histological appearances of a corpus luteum and corpus albicans may have resulted from a collapsed, incompletely mature antral follicle without true LH surge-triggered ovulation. Apparent ovulation in phenotypic men has been reported previously in $46, \mathrm{XX}, 46, \mathrm{XX} / 46, \mathrm{XY}, 46, \mathrm{XX} / 47, \mathrm{XXY}$ DSDs (Table 2, summary of case reports); however, this is the only case of a 46,XX SRY -ve ovotesticular DSD from SOX9 duplication presented in Table 2.

The presence of the $\mathrm{Y}$ chromosome is associated with risk of malignancies in a dysgenic gonad. The patient's 46 , XX karyotype on all cell lines tested, suggests his risk of gonadoblastoma is low. However, based on a single case report of a Sertoli cell tumor in phenotypic male with 46 XX ovotesticular DSD (13), his follow-up will include regular scrotal ultrasound surveillance.

His genetic diagnosis may have implications for the extended paternal family if the SOX9 duplication was inherited. The lack of paternal DNA precluded distinguishing between a de novo germline duplication in the patient or paternal transmission of the SOX9 duplication. The latter has been reported in a fertile $46, \mathrm{XY}$ father carrying a SOX9 or upstream enhancer duplication with transmission to a child with 46,XX karyotype resulting in female-to-male sex reversal $(14,15,16)$. As the paternal uncle and all his sons were fertile, there is no evidence to suggest this was paternally inherited.
Previously reported SOX9 duplications are summarized in Table 3, our case is unique in his presentation with a testicular mass from ovulation and with evidence of probable multiple ovulations.

Consensus statement on management of intersex disorders of the Paediatric Endocrine Society and European Society for Paediatric Endocrinology at Chicago International Consensus Conference on Intersex (Chicago consensus) of 2006 (17) defined DSDs as congenital conditions in which development of chromosomal, gonadal or anatomic sex is atypical. The proposed nomenclature emphasizes on the knowledge of karyotype, which is key in categorizing the DSDs as (1) sex chromosome DSDs (variation in the number of sex chromosomes e.g. Turner's syndrome 45,X; Klinefelter's syndrome 47,XXY; mixed gonadal dysgenesis, etc.), (2) 46,XY DSDs and (3) 46,XX DSDs as described in Table 4 (18). Table 4 also demonstrates categories of 46,XX DSDs that can cause virilization or male phenotype in $46, \mathrm{XX}$ individuals as presented in our present case.

Management of DSDs should integrate the medical aspects of care with the psychosocial needs of the patient. Currently, there are no recommendations for sex assignment in neonates who have DSD. Any surgical procedure in children that leads to irreversible change must be considered with utmost caution (18). Ideally, the surgical procedure should also aim to preserve fertility in the most optimal way. In general, individuals with 46,XY DSD have an increased risk of malignancy may need prophylactic gonadectomy if indicated. Treatment is ideal in a multidisciplinary setting with considerations to genetic (implications to family and 
including reproductive recurrence risks), psychological aspects (sensitive individualized counseling including patient gender identity and preference), endocrinological (hormone replacement), surgical (cosmetic, prophylactic gonadectomy) fertility preservation, reproductive opportunities and metabolic health (cardiovascular and bones).

There are still uncharacterized genes causing DSD. Such DSDs are very rare and require a careful systematic, sensitive approach to diagnosis and management of the diagnostic and ethical challenges. Clinical assessment with karyotype (including $S R Y$ expression) and subsequent determination of the presence or absence of Müllerian structures are essential early investigations in any case of DSD. The sophisticated genetic diagnoses now feasible should be undertaken as the basis for genetic counseling of the extended family in any more complex cases.

\section{Declaration of interest}

The authors declare that there is no conflict of interest that could be perceived as prejudicing the impartiality of the research reported.

\section{Funding}

This research did not receive any specific grant from any funding agency in the public, commercial or not-for-profit sector

\section{Patient consent}

A written informed consent has been obtained from the patient for publication of the submitted article and accompanying images.

\section{Author contribution statement}

The article was conceived and written by $\mathrm{N}$ Shankara Narayana under the supervision of D J Handelsman and S M Twigg. A M Kean, A Vasilaras, $L$ Ewans and $G$ Watson were involved in the clinical care and organized the relevant investigations and revision of the manuscript. T Ohnesorg, $\mathrm{K} \mathrm{L}$ Ayers and A Sinclair performed the genetics investigations of the diagnosis and contributed to the manuscript.

\section{References}

1 Ohnesorg T, Turbitt E \& White SJ 2011 The many faces of MLPA. Methods in Molecular Biology 687 193-205. (doi:10.1007/978-1-60761944-4_13)

2 Ohnesorg T, van den Bergen JA, Belluoccio D, Shankara-Narayana N, Kean A-M, Vasilaras A, Ewans L, Ayers KL \& Sinclair AH 2017 A duplication in a patient with 46 ,XX ovo-testicular disorder of sex development refines the SOX9 testis-specific regulatory region to 24 kb. Clinical Genetics. Epub ahead of print. (doi:10.1111/cge.12976)
3 Kashimada K \& Koopman P 2010 Sry: the master switch in mammalian sex determination. Development 137 3921-3930. (doi:10.1242/dev.048983)

4 Sinclair AH, Berta P, Palmer MS, Hawkins JR, Griffiths BL, Smith MJ, Foster JW, Frischauf AM, Lovell-Badge R, Goodfellow PN 1990 A gene from the human sex-determining region encodes a protein with homology to a conserved DNA-binding motif. Nature 346 240-244. (doi:10.1038/346240a0)

5 Jiang T, Hou C-C, She Z-Y \& Yang W-X 2013 The SOX gene family: function and regulation in testis determination and male fertility maintenance. Molecular Biology Reports 40 2187-2194. (doi:10.1007/ s11033-012-2279-3)

6 Vidal VPI, Chaboissier M-C, de Rooij DG \& Schedl A 2001 Sox 9 induces testis development in XX transgenic mice. Nature Genetics $\mathbf{2 8}$ 216-217. (doi:10.1038/90046)

7 Huang B, Wang S, Ning Y, Lamb AN \& Bartley J 1999 Autosomal XX sex reversal caused by duplication of SOX9. American Journal of Medical Genetics 87 349-353. (doi:10.1002/(SICI)10968628(19991203)87:4<349::AID-AJMG13>3.0.CO;2-N)

8 Yamauchi Y, Riel JM, Ruthig VA, Ortega EA, Mitchell MJ \& Ward MA 2016 Two genes substitute for the mouse Y chromosome for spermatogenesis and reproduction. Science 351 514-516. (doi:10.1126/science.aad1795)

9 Barrionuevo F, Bagheri-Fam S, Klattig J, Kist R, Taketo MM, Englert C \& Scherer G 2006 Homozygous inactivation of Sox9 causes complete XY sex reversal in mice. Biology of Reproduction 74 195-201. (doi:10.1095/biolreprod.105.045930)

10 Foster JW, Dominguez-Steglich MA, Guioli S, Kwok C, Weller PA, Stevanovic M, Weissenbach J, Mansour S, Young ID, Goodfellow PN, et al. 1994 Campomelic dysplasia and autosomal sex reversal caused by mutations in an SRY-related gene. Nature 372 525-530. (doi:10.1038/372525a0)

11 Seymour PA 2014 Sox9: a master regulator of the pancreatic program. Review of Diabetic Studies 11 51-83. (doi:10.1900/RDS.2014.11.51)

12 Cheung M \& Briscoe J 2003 Neural crest development is regulated by the transcription factor Sox9. Development 130 5681-5693. (doi:10.1242/dev.00808)

13 Gunasegaram R, Mathew T \& Ratnam S 1981 Sertoli cell tumour in a true hermaphrodite: suggestive evidence for ectopic gonadotrophin production by the tumour. Case report. British Journal of Obstetrics and Gynaecology 88 1252-1256. (doi:10.1111/j.1471-0528.1981.tb01207.x)

14 Kim G-J, Sock E, Buchberger A, Just W, Denzer F, Hoepffner W, German J, Cole T, Mann J, Seguin JH, et al. 2015 Copy number variation of two separate regulatory regions upstream of SOX9 causes isolated 46,XY or 46,XX disorder of sex development. Journal of Medical Genetics 52 240-247. (doi:10.1136/jmedgenet-2014-102864)

15 Benko S, Gordon CT, Mallet D, Sreenivasan R, Thauvin-Robinet C, Brendehaug A, Thomas S, Bruland O, David M, Nicolino M, et al. 2011 Disruption of a long distance regulatory region upstream of SOX9 in isolated disorders of sex development. Journal of Medical Genetics 48 825-830. (doi:10.1136/jmedgenet-2011-100255)

16 Cox JJ, Willatt L, Homfray, Tessa MB \& Woods CG 2011 A SOX9 duplication and familial 46,XX developmental testicular disorder. New England Journal of Medicine 364 91-93. (doi:10.1056/ NEJMc1010311)

17 Lee PA, Houk CP, Ahmed SF \& Hughes IA 2006 Consensus statement on management of intersex disorders. International Consensus Conference on Intersex. Pediatrics 118 e488-e500. (doi:10.1542/ peds.2006-0738)

18 Hughes IA, Houk C, Ahmed SF \& Lee PA 2006 Consensus statement on management of intersex disorders. Journal of Pediatric Urology 2 $148-162$. 